bản thân mắc sốt rét và tiền sử gia đình mắc sốt rét cần tăng cường truyền thông giáo dục kiến thức phòng chống SR nhiều hơn nhằm nâng cao sự hiểu biết và góp phần hạn chế các tác hại do SR gây ra.

\section{TÀI LIỆU THAM KHẢO}

1. Lê Xuân Hùng và Nguyễn Mạnh Hùng (2010), "Bệnh SR và chiến lược phòng chống SR ở Việt Nam", Nhà xuất bản Y họ̣ Hà Nội,

2. Triệu Nguyên Trung (2007), "Thực trạng SR 2001-2006 và các giải pháp can thiệp ở khu vực miên Trung - Tây Nguyên", Kỷ yểu công trình NCKH 2001 - 2006, NXB y học, 12 - 25.

3. V Oluwasanmi Amusan, Yahaya Abdullahi Umar và Philip Anthony Vantsawa (2017), "Knowledge, attitudes and practices on malaria prevention and control among private security guards within Kaduna Metropolis, Kaduna StateNigeria", Sci J Public Health, 5240-5.
4. Bộ Y tế - Viện Sốt rét-KST-CT TW (2010), Đánh giá công tác PCSR năm 2009 và triển khai kế hoach PCSR năm 2011, Báo cáo nội bộ, Place Publishe.

5. Viển sốt rét - Ký sinh trùng - Cốn trùng Quy Nhơn (2019), Sốt rét tại khu vực miền Trung-Tây Nguyên năm 2019-Nguy cơ và thách thức, Báo cáo nội bộ, Place Publishe.

6. Luân Thị Nhung (2018), Kiến thức, thái độ, thực hành phòng chóng sốt rét của đồng bào S'tiêng tai huyện Bù Đăng tỉnh Bình Phước năm 2018, Luận văn tốt nghiệp, Đại học Y Dược TP. Hồ Chí Minh

7. Lê Hữu Hòa (2014), Kiến thức phòng chống sốt rét của đồng bào S'tiêng, Mnông và các yếu tố liên quan tai xã Đồng Nai và Đắk Nhau, huyện Bù Đăng-Bình Phước năm 2004, Luận văn tốt nghiệp chuyên khoa I, Đai học Y Dược TP HồChí Minh

8. Vũ Ngọc Tuấn (2017), Kiến thức, thực hành về phòng chống sốt rét của người dân xã Bù Gia Mập, huyện Bù Gia Mập, tỉnh Bình Phước năm 2017, Luận văn tốt nghiệp, Đại học Y Dược TP Hồ Chí Minh,

\title{
THỰC TRANG THỰC HIỆN QUY TRÌNH LÂM SÀNG CHẨN ĐOÁN VÀ ĐIỀU TRI ĐTĐ TÝP 2 TẠI TRUNG TÂM Y TẾ HUYỆN TỨ KỲ, TỈNH HẢI DƯƠNG NĂM 2019
}

\section{TÓM TẮT}

Cùng với sư gia tăng nhanh chóng của tỷ lệ hiện mắc và mới mắc của đái tháo đường (ĐTĐ) týp $\dot{2}$, việc tuân thủ theo quy trình khám chữa bệnh sẽ làm giảm thiểu tối đa những sai sót trong sàng lọc và chẩn đoán bệnh. Căn cứ vào những nội dung tại Quyết định số: 3798/QĐ-BYT ngày 27/8/2017 của Bộ Y tế về việc ban hành quy trình quy trình lâm sàng chẩn đoán và điều trị ĐTĐ týp 2, chúng tôi tiến hành nghiên cứu mô tả thực trang thực hiện quy trình lâm sàng chẩn đoán và điểu trị ĐTĐ týp 2 tai Trung tâm $Y$ tế huyện Tứ Kỳ, năm 2019. Nghiên cứu sử dụng phương pháp nghiên cứu mô tả cắt ngang, thu thập thông tin qua phỏng vấn 215 bênh nhân và rà soát hồ sơ bênh án của những bệnh nhân đó. Kết quả nghiên cứu cho thấy thông tin hành chính của người bênh được hoàn thiện tương đối đầy đủ trong hồ sơ bệnh án (HSBA) tỷ lệ trung bình có thực hiện đạt 92,8\%. Tỷ lệ có thực hiện đầy đủ các nội dung trong 7 bước của quy trình từ việc phỏng vẩn người bệnh là $79,4 \%$ và từ việc thu

\footnotetext{
${ }^{1}$ Phòng Y tế, UBND huyện Tứ Kỳ, tỉnh Hải Dương Đại học Y tế Công cộng

${ }^{3}$ Học Viện Quân Y

${ }^{4}$ Trường Đại hoc Y Dước Thái Bình

Chịu trách nhiệm chính: Khương Tùng Ân

Email: tungankhuong.kta@gmail.com

Ngày nhận bài: 9.9.2021

Ngày phản biên khoa học: 27.10.2021

Ngày duyệt bài: 10.11.2021
}

\author{
Khương Tùng Ân', Nguyễn Quỳnh Anh², \\ Lê Đình Tuân ${ }^{3}$, Ngô̂ Văn Mạnh
}

thập số liệu từ HSBA là 83,5\%. Tuy nhiên, tỷ lệ thông tin "có thực hiện" từ phỏng vấn đều cho tỷ lệ thấp hơn từ HSBA. Nghiên cứu đưa ra khuyến nghị về việc chuẩn hóa và ban hành các quy trình chuyên môn, tăng cường kiểm tra giám sát chặt chẽ theo quy định của Bộ Y tế trong đó có Quy trình lâm sàng chẩn đoán và điều trị ĐTĐ týp 2 nhằm giảm tỷ lệ không thực hiện các nội dung quy trình chuyên môn tại Trung tầm $Y$ tế huyên Tứ Kỳ̀.

Tư khoá: đái tháo đường týp 2, quy trình chẩn đoán và điều trị đái tháo đường týp 2.

\section{SUMMARY \\ CURRENT IMPLEMENTATION OF THE \\ CLINICAL DIAGNOSIS PROCESS AND \\ TREATMENT FOR PATIENTS WITH TYPE 2 \\ DIABETE AT TU KY DISTRICT HEALTH \\ CENTER, HAI DUONG PROVINCE 2019}

Along with the rapid increase in the incidence and prevalence of type 2 diabetes, adherence to medical examination and treatment procedures would minimize errors in screening and diagnos. Based on the contents of Decision No. 3798/QD-BYT dated August 27, 2017 of the Ministry of Health stipulating the implementation of clinical procedures for diagnosis and treatment of type 2 diabetes, we conducted this research. This study used descriptive research method, gathered information through interviews with 215 patients and reviewed the medical records of those patients. The research results showed that the administrative information of the patient was relatively 
complete in the medical record, the average rate achieved $92.8 \%$. The rate of full implementation of process in 7 steps of the process from interviewing patients was $79.4 \%$ and from data collection from medical record was $83.5 \%$. However, the percentage of "complete" information from the interviews all gave a lower rate from medical record. The study also made recommendations on standardization and promulgation of professional procedures, strengthening strict monitoring and supervision in accordance with the regulations of the Ministry of Health including the clinical process of diagnosis and treatment of type 2 diabetes.

Keywords: Type 2 diabetes mellitus, process of diagnosis and treatment of type 2 diabetes mellitus.

\section{I. ĐẶT VẤN ĐỀ}

ĐTÐ là một trong các bệnh mạn tính không lây nhiễm có xu hướng gia tăng trên toàn cầu. Các biến chứng liên quan đến bệnh ĐTĐ gây tử vong và tăng gánh nặng chi phí cho người bệnh, gia đình và xã hội [1]. Việt Nam cũng là nước đang đối mặt với sự gia tăng ngày càng nhanh của bệnh ĐTĐ. Năm 2001, tỷ lệ mắc bệnh ĐTÐ của người dân Việt Nam chỉ chiếm $4 \%$ dân số, đến năm 2012 đã tăng lên 5,42\% [6].

Tại Việt Nam, các cơ sở y tế được phân chia từ tuyến Trung ương đến tuyến cớ sở, việc tổ chức khám, sàng lọc, chẩn đoán và điều trị có ý nghĩa to lớn không chỉ làm giảm tải số người bệnh lên các tuyến Trung ương mà còn giúp hiệu quả điều trị bệnh được cải thiện. Năm 2011, tại Trung tâm Y tế huyện Gia Lâm có $29,7 \%$ được xét nghiệm tầm soát glucose 1 tháng/lần, 49,4\% được kiểm tra huyết áp 1 tháng/lần, 46,9\% điều trị bệnh bằng đơn trị liệu, thuận lợi trong quản lý là $100 \%$ người bệnh được khám và điều trị theo Bảo hiểm y tế (BHYT) [1]; Năm 2017, Phạm Văn Sang tiến hành nghiên cứu thực trạng quản lý và điều trị người bệnh ĐTĐ týp 2 tại Bệnh viện đa khoa Tứ Kỳ, Hải Dương, cho thấy tỷ lệ người bệnh đạt mục tiêu kiểm soát đường huyết là $69,3 \%$, tỷ lệ người bệnh tập thể dục theo thời gian khuyến cáo đạt $82,7 \%$, tỷ lệ người bệnh đến khám đúng lịch theo tháng đat 95,2\% [2].

Ngày 27 tháng 8 năm 2017, Bộ Y tế ban hành Quyết định số 3798/QĐ-BYT về Quy trình lâm sàng chẩn đoán và điều trị bệnh ĐTĐ týp 2 . Cho đến nay vẫn chưa có nghiển cứu nào mô tả, đánh giá thực trạng việc thực hiện Quy trình này. Thống kê báo cáo của Trung tâm y tế (TTYT) huyện Tứ Kỳ cho thây tỷ lệ người bệnh vào điêu trị ĐTÐ ngày càng tăng đặc biệt là tỷ lệ bệnh ĐTÐ týp 2. Năm 2014, có 1030 người bệnh và theo báo cáo cuối năm của Phòng khám ĐTĐ đến 15/12/2018 có 1635 người bệnh. Trong đó,
95,2\% là người bệnh ĐTÐ týp 2 [2]. Xuất phát từ những phân tích trên, chúng tôi tiến hành nghiên cứu này với mục tiêu mô tả thực trạng thực hiện quy trình lâm sàng chẩn đoán và điều trị ĐTÐ týp 2 tại Trung tâm Y tế huyện Tứ Kỳ, tỉnh Hải Dương năm 2019.

\section{II. ĐỐI TƯƠ'NG VÀ PHƯƠNG PHÁP NGHIÊN CỨU}

*Đối tượng nghiên cứu: là các bệnh nhân ĐTÐ týp 2 đang được quản lý và điều trị tại TTYT huyện Tứ Kỳ, có HSBA theo dõi định kì, từ tháng 3 đến tháng 6/2019

*Thiết kế nghiên cứu: nghiên cứu mô tả cắt ngang.

*Cõ̃ mẫu: (1) Tài liệu, số liệu thứ cấp: hồ sơ bệnh án của người bệnh ĐTĐ týp 2 tại TTYT huyện Tứ Kỳ, các báo cáo của Phòng khám ĐTĐ, phòng Kế hoạch tổng hợp và phòng Hành chính nhân sự của TTYT huyện Tứ Kỳ.

(2) Nghiên cứu định lượng: nghiên cứu sử dụng công thức tính cỡ mấu cắt ngang:

$$
n=\frac{Z_{1-\alpha / 2}^{2} \times p \times(1-p)}{d^{2}}
$$

Trong đó: p: là tỷ lệ dự đoán số quy trình thực hiện đúng cần quan sát. Do chưa có nghiên cứu nào đánh giá thực trạng thực hiện đúng quy trình lâm sàng chẩn đoán và điều trị ĐTĐ týp 2 nên chọn $\mathrm{p}=50 \%$ để cõ̃ mẫu là lớn nhất;

z: hệ số tin cậy, ứng với độ tin cậy $95 \%$ thì $z$ $=1,96$ với mức ý nghĩa $\mathrm{a}=0,05 ; \mathrm{d}$ : sai số ước lượng của kết quả nghiên cứu của mẫu so với quần thể (ước tính $=0,07$. Số lượng bệnh nhân và HSBA được phỏng vấn và rà soát là 215 .

*Phương pháp thu thập thông tin. Nghiên cứu viên tiến hành quan sát người bệnh đến khám bệnh chẩn đoán và điều trị ĐTÐ từ các bước đăng nhập thông tin đăng ký tại bộ phận tiếp đón. Danh sách người bệnh được tự động cập nhật vào phần mềm hệ thống và được thu thập dữ liệu thông tin qua hồ sơ bệnh án tiến hành hỏi trực tiếp người bệnh làm căn cứ so sánh thông tin.

Căn cứ vào số lượng hồ sơ bệnh án của bệnh nhân chờ tái khám theo ngày mà phòng khám ĐTĐ đang quản lý được lựa chọn ngẫu nhiên để thực hiện quan sát, phỏng vấn và thu thập thông tin cần thiết từ HSBA phục vụ cho nghiên cứu.

Các lần quan sát và hỏi bệnh nhân được chọn theo phương pháp chọn mẫu thuận tiện. Cụ thể: mỗi lượt bệnh nhân đã được lựa chọn nghiên cứu viển là người trực tiếp sử dụng bảng kiểm được xây dựng để quan sát thu thập, thông tin, đánh giá việc thực hiện quy trình lâmm sàng chẩn 
đoán ĐTÐ týp 2 được điều trị và điền vào bảng kiểm đầy đủ các thông tin theo các tiêu chí đánh giá của quy trình, tiếp sau đó là phỏng vấn người bệnh theo những nội dung bảng kiểm để làm cắn cứ đối chứng với những dữ liệu đã thu thập và quan sát được.

*Công cụ và quy trình thu thập số liệu. Sử dụng bộ câu hỏi có cấu trúc dựa vào những nội dung của quy trình lâm sàng chẩn đoán và điều trị ĐTÐ týp 2 được Bộ $Y$ tế quy định tại Quyết định số: 3798/QĐ-BYT ngày 27 tháng 8 năm 2017 để thu thập các thông tin của đối tượng nghiên cứu bằng cách phỏng vấn và các dữ liệu thứ cấp từ HSBA. Tất cả bệnh nhân có HSBA được quản lý và điều trị tại Phòng khám ĐTĐ của TTYT huyện Tứ Kỳ từ 1 năm đến dưới 2 năm khi đến khám và điêu trị, trước khi tiến hành phỏng vấn bệnh nhân được tiếp xúc, giải thích về mục đích tham gia nghiên cứu và chỉ tiến hành phỏng vấn khi có sự chấp nhận hợp tác tham gia của người bệnh. Mỗi bệnh nhẩn được phỏng vấn theo bộ cẩu hỏi phỏng vấn đã xây dựng cùng với đó là các thông tin được thu thập từ HSBA của người bệnh được hoàn thiện theo các nội dung được

*Đạo đaúc nghiền cứu: nghiên cứu được thực hiện khi được Hội đồng đạo đức Trường Đại học Y tế Công Cộng thông qua bằng Quyết định số: 132/2019/YTCC-HD3.

*Xử lý và phân tích số liệu: phiếu phỏng vấn, điều tra thu thập số liệu được xử lý và phân tích bằng phần mềm nhập liệu và phân tích số liệu như: Epi Data, Excel, SPSS...

\section{KẾT QUẢ NGHIÊN CỨU}

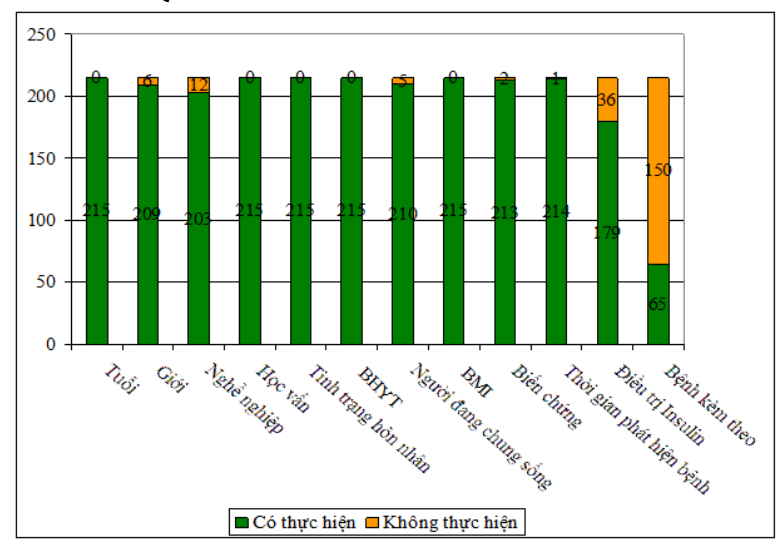

Biểu đồ 1: Thực trạng hoàn thiện thông tin hành chính bệnh nhân ĐTĐ týp 2

Thông tin về tuổi, học vấn, tình trạng hôn nhân, BHYT và chỉ số BMI của người bệnh được ghi nhận $100 \%$ số bệnh án. Thông tin về "điểu trị Insulin" và "bệnh kèm theo" có tỷ lệ không thực hiện cao nhất lần lượt là: $16,7 \%$ và $69,8 \%$.

Bảng 1: Thực trạng thực hiện bước 2: Đánh giá toàn diện tình trạng bệnh

\begin{tabular}{|c|c|c|c|c|}
\hline \multirow[b]{2}{*}{ Nội dung } & \multicolumn{2}{|c|}{ Thực hiện phỏng vấn } & \multicolumn{2}{|c|}{ Thực hiện HSBA } \\
\hline & $\begin{array}{c}\text { Có } \\
\text { n (\%) }\end{array}$ & $\begin{array}{l}\text { Không } \\
\text { n (\%) }\end{array}$ & $\begin{array}{c}\text { Có } \\
\text { n (\%) }\end{array}$ & $\begin{array}{l}\text { Không } \\
\text { n (\%) }\end{array}$ \\
\hline $\begin{array}{l}\text { Khai thác bệnh sử liên quan đến tuổi } \\
\text { khởi phát bệnh }\end{array}$ & $192(89,3)$ & $23(10,7)$ & $215(100)$ & $0(0)$ \\
\hline Chế độ ăn uống, tập luyện & $215(100)$ & $0(0)$ & $215(100)$ & $0(0)$ \\
\hline Tiền sử sử dụng thuốc lá, rượu & $215(100)$ & $0(0)$ & $215(100)$ & $0(0)$ \\
\hline Tầm soát bệnh lý thần kinh & $215(100)$ & $0(0)$ & $215(100)$ & $0(0)$ \\
\hline Các bênh đồng măc khác & $215(100)$ & $0(0)$ & $215(100)$ & $0(0)$ \\
\hline Đo huyễt áp & $213(99,1)$ & $2(0,9)$ & $215(100)$ & $0(0)$ \\
\hline Khám tim mạch & $213(99,1)$ & $2(0,9)$ & $215(100)$ & $0(0)$ \\
\hline Khám đáy mắt & $172(80)$ & $43(20)$ & $211(98,1)$ & $43(1,9)$ \\
\hline Khám da & $201(93,5)$ & $14(6,5)$ & $204(94,9)$ & $11(5,1)$ \\
\hline Khám bàn chân & $207(96,3)$ & $8(3,7)$ & $215(100)$ & $0(0)$ \\
\hline $\begin{array}{c}\text { Làm xét nghiệm ĐTÐ nếu không có } \\
\text { sẵn hoặc đã làm } 3 \text { tháng }\end{array}$ & $215(100)$ & $0(0)$ & 100) & $0(0)$ \\
\hline Phân loại chẩn đoán xác định & $215(100)$ & $0(0)$ & $215(100)$ & $0(0)$ \\
\hline Tư vấn điều trị sau phân loại & $215(100)$ & $0(0)$ & $215(100)$ & $0(0)$ \\
\hline
\end{tabular}

Có $100 \%$ người bệnh cho biết có được thực hiện khai thác các nội dung: chế độ ăn uống, tập luyện; tiền sử sử dụng thuốc lá, rượu, chất gây nghiện; tầm soát bệnh lý thần kinh; các bệnh đồng mắc khác. Có $89,3 \%$ bệnh nhân cho biết có được khai thác bệnh sử liên quan đến tuổi khởi phát bệnh. Tỷ lệ thông tin về việc có thực hiện nội dung quy trình được thu thập tữ HSBA lớn hơn tỷ lệ thu thập được từ việc phỏng vấn trực tiếp người bệnh. 
Bảng 2: Thực trạng thực hiện bước 3: Thiêt lập kế hoạch mục tiêu điều trị

\begin{tabular}{|c|c|c|}
\hline \multirow{2}{*}{ Nội dung } & \multicolumn{2}{|c|}{ Thông tín HSBA } \\
\cline { 2 - 3 } & Có thực hiện n (\%) & Không thực hiện n (\%) \\
\hline $\begin{array}{c}\text { Thiết lập mục tiêu điêu trị cho đối } \\
\text { tượng người già và người trưởng } \\
\text { thành không có thai }\end{array}$ & $0(0)$ & $215(100)$ \\
\hline Cá nhân hóa mục tiêu điêuu trị & $215(100)$ & $0(0)$ \\
\hline
\end{tabular}

$100 \%$ bệnh nhân không được thiết lập mục tiêu điều trị cho tất cả các đối tượng là người già và người trưởng thành không có thai và $100 \%$ bệnh nhân đều được thực hiện cá nhân hóa mục tiêu điêu trị.

Bảng 3: Thực trạng thực hiện bước 4: Lựa chọn thuốc và phương pháp điều trị

\begin{tabular}{|c|c|c|c|c|c|}
\hline \multirow{2}{*}{$\begin{array}{c}\text { Nội dung thực } \\
\text { hiện } \\
\mathbf{n ~ ( \% ) ~}\end{array}$} & $\begin{array}{c}\text { Tơn trị liệu } \\
\text { và thay đổi } \\
\text { lối sống }\end{array}$ & $\begin{array}{c}\text { Liệu pháp 2 } \\
\text { thuốc và thay } \\
\text { đổi lối sống }\end{array}$ & $\begin{array}{c}\text { Liệu pháp 3 } \\
\text { thuốc và thay } \\
\text { đổi lối sống }\end{array}$ & $\begin{array}{c}\text { Liệu pháp } \\
\text { tiêm phối hợp } \\
\text { (Insulin) }\end{array}$ & \multirow{2}{*}{ Tổng } \\
\hline Phỏng vấn & $81(37,7)$ & $123(57,2)$ & $0(0)$ & $11(5,1)$ & $215(100)$ \\
\hline HSBA & $81(37,7)$ & $123(57,2)$ & $0(0)$ & $11(5,1)$ & $215(100)$ \\
\hline
\end{tabular}

$100 \%$ bệnh nhân được phỏng vấn và thu thập thông tin từ HSBA đều được thực hiện việc lựa chọn thuốc và phương pháp điều trị. Không có sự khác biệt giữa tỷ lệ thực hiện các nội dung giữa phỏng vấn và thu thập thông tin từ HSBA.

Bảng 4: Thực trạng thực hiện bước 5: Theo dõi kiểm soát đường huyêt

\begin{tabular}{|c|c|c|c|c|}
\hline \multirow{2}{*}{ Nội dung } & \multicolumn{4}{|c|}{ Thông tin } \\
\cline { 2 - 5 } & \multicolumn{2}{|c|}{ Thực hiện phỏng vấn } & \multicolumn{2}{|c|}{ Thực hiện HSBA } \\
\cline { 2 - 5 } & $\begin{array}{c}\text { Có } \\
\mathbf{n}(\%)\end{array}$ & $\begin{array}{c}\text { Không } \\
\mathbf{n}(\%)\end{array}$ & $\begin{array}{c}\text { Có } \\
\mathbf{n}(\%)\end{array}$ & $\begin{array}{c}\text { Không } \\
\mathbf{n}(\%)\end{array}$ \\
\hline $\begin{array}{c}\text { Theo dõi kiểm soát đường } \\
\text { huyết mục tiêu (Đo HbA1C) }\end{array}$ & $215(100)$ & $0(0)$ & $215(100)$ & $0(0)$ \\
\hline $\begin{array}{c}\text { Phân loại người bênh đạt } \\
\text { mục tiêu điêu trị }\end{array}$ & $0(0)$ & $215(100)$ & $0(0)$ & $215(100)$ \\
\hline
\end{tabular}

Số liệu thông tin phỏng vấn và thu thâp HSBA cho thây $100 \%$ bệnh nhân đều được thực hiện xét nghiệm $\mathrm{HbA1C}$ nhằm mục đích kiểm soát đường huyết mục tiêu. Tuy vậy, sau khi có kết quả xét nghiệm $\mathrm{HbA1C}$ thực hiện nội dung quy trình kiểm soát đường huyết mục tiêu thì không có việc phân loại nhóm bệnh nhân "đạt mục tiêu kiểm soát" hay "không đạt mục tiêu kiểm soát".

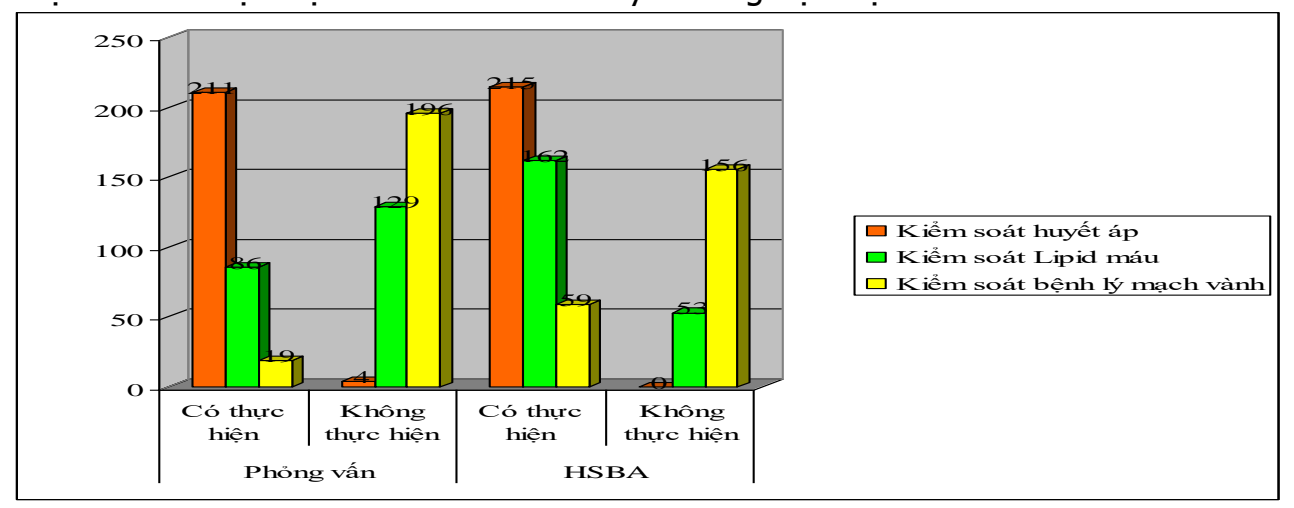

Biểu đồ 2: Thức trạng thức hiện bước 6: Quản lý nguy cơ và bệnh tim mạch

Thông tin ở cả 3 nội dung quy trình quản lý nguy cơ và bệnh tim mạch từ phỏng vấn đều cho kết quả có thực hiện thấp hơn khi thu thập thông tin này từ HSBA. Quy trình kiểm tra huyết áp khi được phỏng vấn chỉ có 211 (tỷ lệ $98,1 \%$ ), bệnh nhân trả lời là có được kiểm tra huyết áp còn trong hồ sơ bệnh án thì cả 215 hồ sơ (tỷ lệ 100\%) bệnh nhân đều thể hiện được kiểm soát huyết áp trong những lần tái khám. Sự chênh lệch này rõ ràng hơn ở quy trình kiểm soát lipid máu và kiểm soát bệnh lý mạch vành khi có lần lượt là $40 \%$ và $8,8 \%$ bệnh nhân được hỏi trả lời là có được kiểm soát trong khi tỷ lệ này được thống kê khi điều tra thông tin từ HSBA lần lượt là 75,3\% và 27,4\%. 


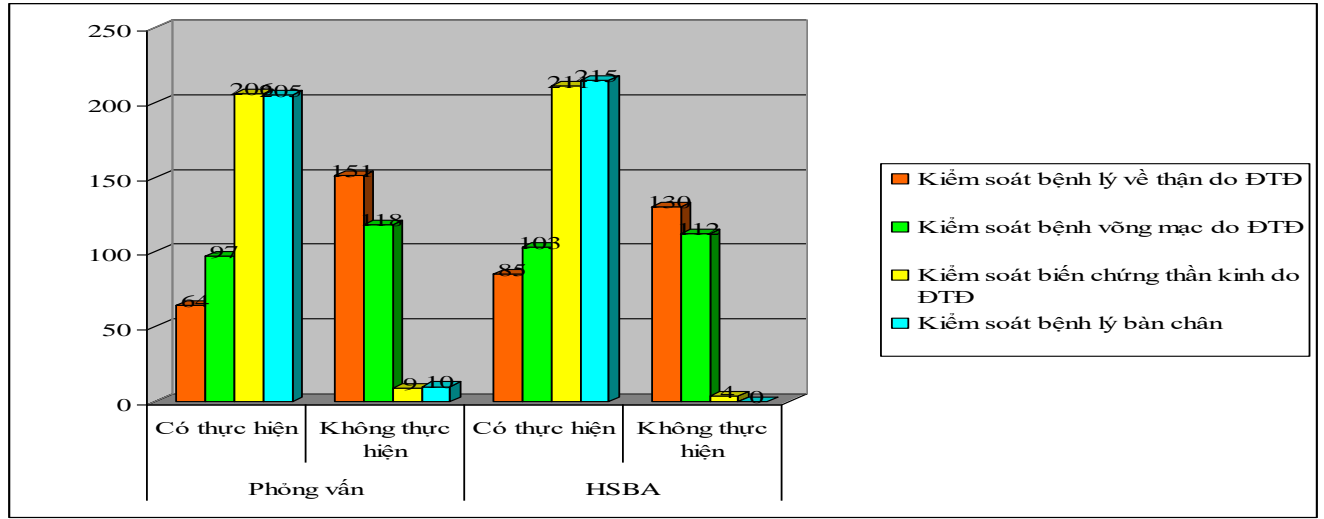

Biểu đồ 3: Thực trạng thực hiện bước 7:

Kiểm soát biến chứng mạch máu nhỏ và chăm sóc bàn chân

Tỷ lệ thực hiện hai bước này từ việc thu thập số liệu trong HSBA của người bệnh không có sự khác biệt nhiều, cụ thể, tỷ lệ thực hiện bước kiểm soát biến chứng thần kinh do ĐTĐ và kiểm soát bệnh lý bàn chân lần lượt là $98,1 \%$ và $100 \%$. Trong khi đó tỷ lệ thực hiện bước kiểm soát bệnh lý về thận do ĐTĐ và kiểm soát bệnh võng mạc do ĐTĐ từ việc phỏng vấn chỉ đạt tỷ lệ lần lượt là $29,8 \%$ và $45,1 \%$.

Bảng 5. Thực trạng thực hiện quy trình lâm sàng chẩn đoán và điều trị ĐTĐ týp 2

\begin{tabular}{|c|c|c|c|c|}
\hline \multirow{2}{*}{ Nội dung } & \multicolumn{4}{|c|}{ Thông tin } \\
\cline { 2 - 5 } & \multicolumn{2}{|c|}{ Thực hiện phỏng vấn } & \multicolumn{2}{c|}{ Thực hiện HSBA } \\
\cline { 2 - 5 } & Có [n (\%)] & Khồng [n (\%)] & Có [n (\%)] & Khống [n (\%)] \\
\hline Bước 1 & 100 & 0 & 100 & 0 \\
\hline Bước 2 & 90,8 & 9,2 & 95,3 & 4,7 \\
\hline Bước 3 & - & - & 100 & 0 \\
\hline Bước 4 & 100 & 0 & 100 & 50 \\
\hline Bước 5 & 50 & 50 & 50 & 32,4 \\
\hline Bước 6 & 48,9 & 51,1 & 67,6 & 28,6 \\
\hline Bước 7 & 66,5 & 33,5 & 71,4 & \\
\hline
\end{tabular}

Tỷ lê thực hiện từ việc phỏng vấn người bệnh luôn thấp hơn tỷ lệ có thực hiện khi thu thập số liệu từ HSBA. Các nội dung quy trình tại bước 1 , bước 2 và bước 4 được thực hiện tốt. Quy trình thực hiện bước 3 tỷ lệ thực hiện trung bình đạt $100 \%$ người bệnh được thiết lập mục tiêu điều trị nhưng nếu căn cứ theo nội dung hướng dẫn về việc phân loại mục tiêu điều trị người bệnh theo đối tượng người già và người trưởng thành không có thai thì không có người bệnh nào được thực hiện việc phân loại này.

\section{BÀN LUẬN}

Các bước của quy trình lâm sàng chẩn đoán và điều trị ĐTÐ týp 2 được quy định tại Quyết định số 3798/QĐ-BYT:

ở bước 1: hầu hết các nội dung thông tin hành chính của người bênh đều được thực hiện với tỷ lệ từ $83,3 \%$ trở lên, các nội dung: tuổi, học vấn, tình trạng hôn nhân, BHYT và chỉ số BMI của người bệnh đều được thực hiện với tỷ lệ $100 \%$. Nghiên cứu của tác giả Cortesz-Dias N. và cộng sự (2010) thấy cán bộ nhân viên không có đủ thời gian để đưa ra những nội dung tư vấn cần thiết cũng như hợp lý với từng người bệnh. Trong nghiên cứu của tác giả Arjan BREGU và cộng sự (2012) [7] cũng đưa ra các khuyến nghị: giáo dục kiến thức thay đổi lối sống ở người bệnh ĐTÐ giúp đảm bảo duy trì kiểm soát đường huyết và theo dõi các tình trạng biến chứng.

Ở bước 2: quy trình được thực hiện với tỷ lệ trung bình đạt $93,1 \%$. Tuy vậy, cũng có những nôi dung như: khám đáy mắt và khám tuyến giáp có những sai lệch số liệu thông tin lớn giữa phỏng vấn bệnh nhân và dữ liệu từ HSBA, các cán bộ nhân viên phòng khám ĐTÐ cũng cho biết việc hoàn thiện nội dung này trong HSBA chỉ để mang tính thủ tục còn thực tế chỉ có người bệnh nào có biểu hiện của bệnh lý tuyến giáp thì Bác sĩ mới thực hiện khám. Những nội dung này cũng được tác giả Võ Bảo Dũng (2008) [4] và tác giả Hoàng Thị Đợi, Nguyễn Kim Lương (2015) [3] nêu ra trong các nghiên cứu. Tuy nhiên, trong các nghiên cứu đã nêu tác tập trung đánh giá tỷ lệ người bệnh ĐTĐ liên quan đến các vấn đề nói trên bằng việc phân tích bệnh học lâm 
sàng và xét nghiệm cận lâm sàng còn trong nghiên cứu của chúng tôi lại tập trung mô tả việc có hay không thực hiện và các yếu tố ảnh hưởng đến việc thực hiện những nội dung quy trình.

Bước 3: thiết lập kế hoạch mục tiêu điều trị: kết quả thu thập số liệu từ HSBA cho thấy không có HSBA nào được thể hiện rõ việc thiết lập kế hoạch mục tiêu điều trị cho đối tượng ngưới già và người trưởng thành không có thai như trong hướng dẫn của quy trình. Tuy vậy, Bác sĩ phụ trách công tác điêu trị của phòng khám ĐTĐ đã thay thế việc phải thiết lập mục tiêu điều trị cho từng nhóm đối tượng như trong hướng dẫn của quy trình bằng việc thực hiện tầm soát đường huyết của mỗi người bệnh tại các lần tái khám và thiết lập mục tiêu điều trị với từng người bệnh được gọi là cá nhân hóa mục tiêu điêu trị.

Bước 4: lựa chọn thuốc và phương pháp điều trị: kết quả từ việc phỏng vấn và thu thập thông tin từ HSBA cho thấy $100 \%$ người bệnh đều được thực hiện việc lựa chọn thuốc và phương pháp điều trị là 1 trong 4 nội dung gồm có: đơn trị liệu và thay đổi lối sống; liệu pháp 2 thuốc và thay đổi lối sống; liệu pháp 3 thuốc và thay đổi lối sống; liệu pháp tiêm phối hợp (điều trị với Insulin). Tuy vậy, do các vấn đề liên quan đến nguồn thuốc duyệt từ BHYT mà không có người bệnh nào được sử dụng liệu pháp 3 thuốc và thay đổi lối sống trong quá trình điều trị. Những nội dung này được tác giả Braga $M$. và cộng sự (2010) nghiên cứu 3.002 người bệnh điều trị ngoại trú mắc bênh ĐTÐ týp 2 tại cơ sở chăm sóc sức khoẻ ban đầu ở Canada [8] cho thấy $11 \%$ không được điều trị ĐTĐ, $28 \%$ dùng đơn trị liệu.

Bước 5: theo dõi kiểm soát đường huyết: việc theo dõi kiểm soát đường huyết của người bệnh ĐTÐ được cán bộ nhân viên phòng khám ĐTÐ của TTYT thực hiện tốt khi tất cả 215 người bệnh được phỏng vấn đều trả lời có được thực hiện xét nghiêm định lượng $\mathrm{HbA1C}$ ở mỗi lần khám/tái khám; thông tin thu thập đối chiếu từ HSBA cũng được ghi nhận các chỉ số định lượng HbA1C của người bênh ở mỗi lần tái khám. Tuy vâyy, nôii dung phân lioại người bênh đat mục tiêu điều trị/không đạt mục tiêu điều trị không được thực hiện do HSBA của người bệnh được các cán bộ nhân viên Phòng khám ĐTĐ quản lý phân loại theo đia chỉ nơi cư trú của người bênh (xã/thị trấn) cùng với đó là việc áp dụng phương pháp cá nhân hóa muc tiêu điều trí.

Bước 6 và bước 7: tỷ lệ chung về thông tin có làm từ HSBA luôn lớn hớn thông tin có làm từ việc phỏng vấn. Cụ thể: nội dung kiểm soát huyết áp được thực hiện tốt khi có 100\% HSBA thể hiện rõ chỉ số huyết áp tại mỗi lần tái khám của người bệnh, nội dung kiểm soát biến chứng thần kinh do ĐTĐ và kiểm soát bệnh lý bàn chân được thực hiên tốt với trên $95 \%$. Số liêu thu thập được trong nghiên cứu phản ánh thực tế vấn đề này do hầu hết những người bệnh ĐTÐ có triêuu chứng bênh lý mach vành sẽ được chuyển lên bệnh viện chuyển khoa tuyến cao hơn. Nghiên cứu của tại Việt Nam, cũng chỉ ra những yếu tố trong nội dung kiểm soát huyết áp như việc thấy rằng $62,4 \%$ số người bệnh chấp hành tốt kiểm soát huyết áp; 32,7\% người bệnh được kiểm soát tốt lipid máu [7].

Một số hạn chế của nghiên cứu: do nguồn lực và thời gian nghiên cứu có hạn nên chỉ tiến hành lựa chọn được các khía cạnh, nội dung phù hợp cho nghiên cứu, vẫn còn một số nội dung mang tính lâm sàng chuyên sâu mà trong giới hạn nghiên cứu của đề tài chưa thể thực hiện. Chưa có nghiên cứu liên quan nào được chúng tôi tìm thấy có sự tương đồng về việc đánh giá thực trang thực hiện quy trình lâm sàng chẩn đoán và điều trị ĐTĐ týp 2 tại các cơ sở y tế quản lý và điều trị ĐTĐ týp 2 ở Việt Nam, điều này khiến chúng tôi khó khăn trong việc đưa ra những kết quả so sánh một cách khách quan.

\section{KẾT LUẬN}

Thông tin hành chính của người bệnh được hoàn thiện tương đối đầy đủ trong HSBA. Hầu hết các thông tin đều được hoàn thiện chiếm tỷ lê trên $80 \%$. Tỷ lê trung bình có thực hiên đầy đủ các nội dung trong 7 bước của quy trình từ việc phỏng vấn người bệnh là $79,4 \%$ và từ việc thu thập số liệu từ HSBA là 83,5\%.

Nội dung quy trình của các bước được tổng hợp từ việc phỏng vấn người bệnh và thông tin thu thập từ HSBA ở chẩn đoán, thiết lập mục tiêu điều trị và lựa chọn phương pháp điều trị đều được thực hiện đầy đủ với tỷ lệ là $100 \%$; nội dung quy trình của các bước đánh giá tình trạng bênh được thực hiện với tỷ lệ thu thập thông tin bằng việc phỏng vấn và từ HSBA đều cho tỷ lệ thấp hơn; nôi dung thực hiện quy trình của bước theo dõi kiểm tra glucose máu với tỷ lệ trung bình ở cả việc phỏng vấn người bệnh và thu thập thông tin từ HSBA đều chỉ đạt $50 \%$.

\section{KHUYẾN NGH!}

Áp dụng các quy trình chuyên môn đã được chuẩn hóa cùng với việc đào tạo nâng cao trình độ chuyên môn của cán bộ nhân viên và tăng cường công tác kiểm tra giám sát giúp nâng cao hiệu quả công tác quản lý các hoạt động chuyên mồn nói chung, thực hiện tốt quy trình chuyên 
môn lâm sàng chẩn đoán và điều trị ĐTĐ nói riêng tại TTYT huyện Tứ Kỳ, tỉnh Hải Dương.

\section{TÀl LIÊU THAM KHẢO}

1. Vũ Thị Tuyết Mai (2011), "Thực trạng công tác quản lý điều trị bênh ĐTĐ týp 2 tại Trung tâm $Y$ tế huyện Gia Lâm nẳm 2011", Luận văn thạc sĩ Quản lý Bệnh viện, Trường Đai học Y tễ Công Cộng.

2. Phạm Văn Sang (2017), "Thực trang quản lý và điêu trị người bệnh ĐTĐ týp 2 tại Bệnh viện đa khoa Tứ Kỳ, Hải Dương năm 2017", Luận văn BSCK II, Trướng Đại học Y Thái Bình.

3. Hoàng Thị Đợi, Ngưyến Kim Lương (2015), "Nghiên cứu thực trang bệnh ĐTĐ týp 2 đang điều trị ngoại trú tại Bệnh viện Đa khoa Trung ương Thái Nguyên; Hội nghi khoa học toàn quốc chuyên ngành nội tiết và chuyển hoá lần thứ 3", tr. 900-911.

4. Vố Bảo Dũng (2008), "Nghiên cứu một số đặc điểm lâm sàng, cận lâm sàng và kết quả điều trị người bệnh ĐTĐ tại Bệnh viện Đa khoa tỉnh Bình Định" Tạp chí Y hoc thực hành, $(616$ + 617), tr. 267-273.

5. Hoàng Thị Hẳng và cống sự (2010), "Thực trang điêu trị bệnh ĐTĐ điểu trị tại khoa Nội Bệnh viển Đa khoa Bắc Kạn", Kỷ yếu các đề tài nghiên cứu khoa học - Bệnh viện Đa khoa Bắc Kạn.

6. Phạm Thu Hiền (2017), "Thực trạng việc thực hiện quy trình lấy máu tĩnh mạch của Điều dưỡng viển tại Bệnh viện Nhi trung ương năm 2017", Luận văn Thạc sî́ quản lý Bệnh viện, Trường Đại học Y tế Công Cộng.

7. Diana Ruchugo (2015), "Knowledge, Attitude and Practices of Type Two Diabetes in a Rural Community in Karatina-Nyeri Country", University of Nairobi, pp: 1-101.

8. Gunggu A, Thon CC, Whye Lian C. Predictors of Diabetes Self-Management among Type 2 Diabetes Patients. J Diabetes Res. 2016;2016:915894, Epub 2016 Aug 3. PMID: 27563681.

\section{NHŨ̃NG YẾU TỐ ẢNH HƯỞNG ĐẾN KÍCH THƯớC NHĨ TRÁI TRÊN SIÊU ÂM TIM 3D Ở BỆNH NHÂN RUNG NHĨ KHÔNG DO BỆNH VAN TIM}

\section{TÓM TẮT}

Giãn nhĩ trái là một yếu tố nguy cơ của đột quy và là yếu tố quyết định cho sự thành công của chiến lược kiểm soát nhịp tim ở bệnh nhân rung nhĩ. Tuy nhiên, những yếu tổ liễ̂n quan đến thể tích nhĩ trái ở bệnh nhân rung nhĩ vẫn chưa được hiểu đầy đủ. Mục tiều: Tìm hiểu những yếu tố liên quan đến giãn nhĩ trái trên siêu âm tim 3D ở bệnh nhân rung nhĩ không do bệnh van tim. Đối tượng và phương pháp: Nghiên cứu mô tả cắt ngang tiến hành trên các bệnh nhân rung nhĩ không do bệnh van tim. Tất cả các bệnh nhân được hỏi bệnh, thịăm khám lấm sàng kỹ lưỡng và làm bệnh án theo mẫu, làm một số thăm dò và xét nghiệm sinh hoá, làm ĐTĐ 12 chuyển đạo, làm siêu âm tim 2D và $3 \mathrm{D}$ theo hướng dẫn của Hội Siêu âm Tim Hoa Kỳ. Thể tích nhĩ trái được đánh giá trên siêu âm tim 3D bằng phân mềm Heart Model. Kết quả: Từ 07/2020 đến $07 / 2021$ có 80 bệnh nhân được đưa vào nghiên cứu, tuổi trung bình60,7 \pm 4,8, nam 48.8\%, nữ $51.2 \%$. Thể tích nhĩ trái trên siêu âm tim 3D có mối liên quan với các yếu tố như tiền sử tăng huyết áp $\left(\beta=1,3 \pm 0,9 \mathrm{ml} / \mathrm{m}^{2}\right)$, đái tháo đường $(\beta=0,8 \pm$ $\left.0,2 \mathrm{ml} / \mathrm{m}^{2}\right)$, bệnh thận mạn $\left(\beta=2,4 \pm 0,9 \mathrm{ml} / \mathrm{m}^{2}\right)$, bệnh mạch vành $(\dot{\beta}=2,2 \pm 0,5)$ và rối loạn chức năng tâm trương $\left(\beta=2,3 \pm 4,6 \mathrm{ml} / \mathrm{m}^{2}\right)$. Khi phân tích đa biến, bệnh mạch vành $\left(\beta=2,5 \pm 0,4 \mathrm{ml} / \mathrm{m}^{2}\right)$, bệnh thận mạn $\left(\beta=2,9 \pm 0,3 \mathrm{ml} / \mathrm{m}^{2}\right)$ và rối loạn chức năng tầm trương thất trái $\left(\beta=2,4 \pm 0,4 \mathrm{ml} / \mathrm{m}^{2}\right)$ cho thấy mối liên

*Viện Tim Mạch, Bênh Viện Bạch Mai.

Chịu trách nhiệm chính: Đỗ Doãn Bách

Email: dodoanbach@gmail.com

Ngày nhận bài: 7.9.2021

Ngày phản biện khoa học: 25.10.2021

Ngày duyệt bài: 8.11.2021

\section{Đỗ Doãn Bách*, Nguyễn Thị Thu Hoài*}

quan độc lập với thể tích nhĩ trái ở bệnh nhân rung nhĩ không do bệnh van tim. Kết luận: Rối loạn chức năng tâm trương thất trái, bệnh thận mạn, bệnh mach vành là những yếu tố có ảnh hưởng đển giẩn thể tích nhĩ trái trên siêu âm tim 3D ở các bệnh nhân rung nhĩ không do bệnh van tim. trái

Tư khóa: Rung nhĩ, siêu âm tim 3D, thể tích nhĩ

\section{SUMMARY}

\section{FACTORS AFFECTING LEFT ATRIAL SIZE ONTHREE-DIMENSIONAL ECHOCARDIOGRAPHY IN PATIENTS WITH NON-VALVULAR ATRIAL FIBRILLATION}

Background: Left atrial (LA) enlargement is an important risk factor for incident stroke and a key determinant for the success of rhythm control strategies in patients with atrial fibrillation (AF). However, factors associated with LA volume in AF patients remain poorly understood. Objective: To study factors related to left atrial dilation in patients with non-valvular atrial fibrillation on 3D echocardiography. Methods: A cross-sectional descriptive study was conducted in patients with nonvalvular atrial fibrillation. Data of medical history, clinical examination biochemical tests, ECG were collected. 2D and 3D echocardiography were performed in all participants and analyzed in a standardized manner. Left atrial volume was assessed on 3D echocardiography using Heart Model software. Results: From 07/2020 to 07/2021, 80 patients were included in the study, the mean age was $60.7 \pm 4.8$, male $48.8 \%$, female $51.2 \%$. Hypertension, diabetes mellitus, chronic kidney disease, coronary artery diseaseandleftventriculardiastolicdysfunction were 